\title{
Toward a Cultural-Historical Perspective on the Selection Task
}

\author{
Romain Boissonnade • Valérie Tartas • \\ Michèle Guidetti
}

Published online: 22 January 2014

(C) Springer Science+Business Media New York 2014

\begin{abstract}
Independently of their age, individuals produce weak logical responses when they solve the Wason selection task. Many studies describe conditional reasoning, focusing on intra-individual and general processes. The role of meaning attributed to the situation or the linguistic interpretation of the rules have nevertheless been stressed by pragmatic studies. Few scattered studies show the role of collective situations, of subjects' prior knowledge and of objects in solving the selection task. This paper goes back to the questions raised by the selection task and attempts to place past results into a cultural-historical theoretical framework, which defines a complex and evolving cognitive system, where human beings rely on social exchanges, equip themselves with cultural instruments, create intellectual tools, and give meaning to their experiences. Taking into account such a system is necessary to shed light upon the possibilities for the development of human thinking processes in order to solve selection tasks.
\end{abstract}

Keywords Social interactions · Cultural-historical perspective $\cdot$ Conditional reasoning Selection task · Tools

Invented by Peter Wason $(1966,1977)$, the selection task is actually a classical means to comprehend conditional reasoning. Generally, the participants are presented with four cards and are told that each one of them has a letter on one side and a number on

\footnotetext{
R. Boissonnade $(\bowtie)$

Institut de Psychologie et Education, Université de Neuchâtel, Espace Agassiz, 1, 2000 Neuchâtel, Switzerland

e-mail: romain.boissonnade@unine.ch

V. Tartas $\cdot$ M. Guidetti

Laboratoire U.R.I. Octogone-ECCD, Université de Toulouse II-Le Mirail, Pavillon de la Recherche, 5 Allée Antonio Machado, 31058 Toulouse Cedex 9, France

V. Tartas

e-mail: valerie.tartas@univ-tlse2.fr

M. Guidetti

e-mail: guidetti@univ-tlse2.fr
} 
the other side. Two of these cards are shown with the letter side up (A, D), and two with the number side up $(4,7)$. The following rule is given: "If there is an A on one side, then there is a 4 on the other side." The following question is asked: "Indicate which card(s) you need to turn over in order to judge whether the rule is true". The combination of A ("affirmation of the antecedent") with 7 cards ("negation of the consequent") is the only way to logically test the rule. However, a majority of participants turn the A and 4 cards, or the A card only. These illogical responses illustrate the tendency of people to confirm their background knowledge rather than to refute it by systematically testing it.

A great variety of research studies have explained what conditional reasoning is with respect to this task, essentially considering internal processes. Other studies have enlisted this task but solely to investigate other issues. This paper considers both of these types of studies from an integrative developmental perspective, focused on the relations of cognition with problem-solving situation in the course of development. It thus takes into account both subjective and cultural dimensions of the context of problem-solving in order to provide a socio-cultural approach of reasoning through the WST resolution. In this perspective, environment will not be defined as transparent and univocal, the same for everybody, as it implies considering subject's activities which are always situated and deployed in social contexts. In doing so, this paper tries to support past efforts to understand the extent and forms of conditional reasonning (i.e. Faiciuc 2008; Nickerson 1998). Now our questioning is: what exactly is happening in the Wason selection task's situation? Instead of opening a cognitive black box, we would rather scrutinize the many facets of the socio-cognitive toolbox, that is to say how interactions with objects, interactions with others, and the use of cultural means, shape reasoning on the selection task. How do they potentially channel the development of reasoning on the selection task? Some basic statements are necessary before considering the consequences for future studies. After having depicted the way a Vygotskian paradigm could lead to a socioconstructivist perspective of reasoning about the selection task (I), two dimensions are detailed to support this epistemological turn: the role of interpersonal interactions (II) and the role of material and language mediations (III). We finally identify theoretical and methodological considerations to conclude with research perspectives (IV).

\section{From Constructivism to Socio-Constructivism: Interest in Vygotsky's Paradigm}

In this section, three main features of an epistemological turn are drawn: How to define the role of the subject in the development? How to consider the role of environment? What kind of processes are at stake?

The first question is about the subject we are theorizing about. Children, as well as adults, do poorly in abstract selection tasks, such as in the standard Wason's Selection Task (WST). However, in some of its variants, the majority of responses are "logical" (i.e. they generally follow the standard logic expectations). Therefore, the resulting performances are extremely variable, for instance according to the content of the cards. Such is the case when the rule states that "Every time I go to Manchester, I travel by car" and when the "Leeds" "Manchester" "car" and "train" cards are placed in front of the participant (Wason and Shapiro 1971). Variations of the task have made it possible to distinguish several factors, according to whether the cards contain abstract 
or thematic objects, whether the rule is expressed in causal, descriptive or deontic terms, or whether that rule is based on conventional meanings or not. Many research studies focus on the nature of human reasoning. The cognitive system is then described by consistent and intraindividual processes: task representation, probability algorithms, pragmatic schemas, memory mechanisms, biases, etc.... In these paradigms, the human mind can only react to stimuli, and most of the studies try to understand why this is not happening accordingly to a logical norm, often implicitly considered as the structure of reality. The development of this individual resolving the task is now a much more complex topic. Long after Wason (1968), researchers have had doubts about the possibility of cognitive development in the case of the selection task. But recent studies have discovered a slight progression from the perspective of standard logic as early as adolescence (De Neys and Everaerts 2008; Grosset, Barrouillet and Misuraca 2004; Klaczynski, Schuneman and Daniel 2004; Verzoni and Swan 1995). Although this evolution concerns a minority of participants, the difference in responses is no less radical. This proves that the piagetian approach (Inhelder and Piaget 1958; Piaget 1970), much like the "mental logic" approach (Rips 1994), cannot be completely overwhelmed. A constructivist analysis is helpful to clarify what is developing, and how. In the Piagetian tradition, the Overton team (Müller, Overton and Reene 2001; Overton, Ward, Noveck, Black and O'Brien 1987) studied the construction of logical reasoning structures. According to Overton and Dick (2007), logical necessity is neither an innate reasoning, nor simply the fruit of an inductive generalisation of perceptions of reality, but rather stems from the subjects' organisation of inferences, from sensory motor coordinations to the constitution of a system of representations. For these authors, reasoning is a target-directed thought that coordinates inferences. The individuals evolve because they actively construct reasoning, taking into account task constraints. An equivalent definition is proposed in a socio-cultural perspective: the subject is defined as an active participant; his or her activity is always situated in social contexts, which are interpreted by the subject to act.

A second question is now related to the role given to the environment or context. In the cognitivist paradigm, environmental constraints are generally considered as external (i.e. they do not belong to the cognitive system), and as unconscious influences (i.e. the individuals do not use them voluntarily). The constructivist perspective seems limited too, because it assumes a universal cognitive adaptation to common external structures, implying that all mature reasoning would be coherent with standard logic. Moreover, it still minimizes the role of meanings much like the semantic content of the task (Stenning and Van Lambalgen 2004) or like pragmatic considerations (Sperber, Cara and Girotto 1995). A different constructivism is needed. For Vygotsky (1978; 1994), in agreement with Piaget (1970), early development is determined by both biological inheritance and initial interactions with our physical environment. But in spite of early conditional reasoning abilities (Kalish 1998), radical changes occur during the ontogenesis. The socio-constructivist perspective emphasizes both material and cultural means that an individual can use to modify his or her own thought. The performances are then situated in the specific contexts he or she is going through the mobilization of previous knowledge and of the mediations that contribute to his or her development. Human socialization and the ability to use specific means such as technical instruments or language, can fundamentally alter cognition. The cognitive processes spring from the past generations' prior activities. In this paradigm, logic is a structured discipline, 
involving other tools, and must be distinguished from reasoning. This deep culturalhistorical restructuring of cognition makes it impossible to separate the biological parts of cognitive processes from the cultural ones, and the individual parts from the social ones. Here lie the roots of higher mental functions (interpreting, calculating, analyzing, solving problem...): "all higher mental functions are internalized social relationships. [...] Their composition, genetic structure, and means of action - in a word, their whole nature - is social" (Vygotsky 1981, p. 164). Evaluating an individual response to a selection task without taking into account the social contexts implying mediations, such as tools, language and meanings but also other visible or not, would be reductive.

Finally, what processes could explain a cognitive evolution? Neuropsychology indicates that deep changes of cerebral activity would be associated with learning experiences about conditionals (Houdé and Tzourio-Mazoyer 2003). Now, a better understanding of how those changes occur can be achieved. To reframe the research goal, we suggest here to replace the fascination with the discrepancy between reasoning and logical expectations, by another intriguing phenomenon: in the abstract selection task, we wonder how people could accurately use logical rules, produced by centuries of thoughts about the world, or to reinvent them with their own words. It is now a practical question, related to the functional use of logic. In everyday activities, the conditional problem generally occurs on a social level; for instance we confirm and strengthen our propositions in order to contradict other people. Nickerson (1998) thus stressed the ambiguity to speak about a general confirmation bias. As a result, the individual is not confronted with an unequivocal external context, but rather with some possible universes (Smorti 2008): he does not reason about the validity of a statement but interprets the problem depending on perceived contexts and depending on motives to make hypotheses or suppositions about that context. The human cognition, therefore, is to be defined not only according to a predetermined logical norm. When confronted with problems that are never identical, individuals can actively re-elaborate their means of resolution by going from situation to situation (Brossard 1999). In that case, formal logic is a culturally and historically adapted means between the agent and the problem, admittedly stable, rather than an end in itself. The child learns to control this tool in order to solve a range of problems in a variety of contexts.

A Vygotskian paradigm integrates the social, cognitive and affective dimensions of reasoning into a whole functional and cultural system, and let explore in depth the processes of change. The first objective is to situate the participant in an interindividual dimension and then to consider in this social situation, the specificity of artefacts (objects and language) in use for solving a problem.

\section{An Interpersonal Approach to Conditional Reasoning}

The Vygotskian principle that development proceeds from the interpersonal to the intrapersonal level confers an essential role to social interactions. Group resolution of the selection task revealed influence and decision processes (Oberlé, DrozdaSenkowska and Quémy 2002). Socio-constructivist studies focus more on the interstructuration of the individuals' procedures in order to solve a problem. Peer interactions or interactions with a more competent partner are essential to cognitive development (Bruner 1983; Perret-Clermont and Nicolet 2001). There is no totally 
solitary cognition because the participant is permanently at the core of interpersonal interactions (Matusov 1998). Even when placed "in isolation" or in "individualized" conditions, the child interacts with the experimenter. This involves delineating individuals in interaction as the unit of analysis (Granott 1998; Grossen 2010; Matusov 2007). How do these interactions support or constraint reasoning about the selection task? We suggest to consider effectively on the one hand scaffolding interactions and peer interactions, and on the other hand the consequences of an interindividual system i.e. centration and decentering processes, regulations related to problem content, and finally pragmatic processes.

\section{Reasoning in and Through Scaffolding Interactions}

Vygotsky $(1986 ; 1978)$ was mostly interested in asymmetric tutoring relations, that is, when a more capable individual supports the activity of a novice and the learning process. We know that children use "if... then" conditional statements in their daily conversations with adults (Scholnick and Wing 1995); however the process of acculturation fostered by tutoring remains poorly known. A few studies on conditional problems focus on this type of interaction. According to Green (1995), when adult novices are confronted with WST, guidance by expert adults may bring them to conditional reasoning, for instance, by having them look for counterexamples that falsify the rule. Indeed, it has been proven that finding disabling conditions or alternative causes promotes logical resolution (Cummins 2004). Tutoring also encourages the participants to think about their own reasoning (Stenning and van Lambalgen 2001, 2004). The task is somewhat modified but, nonetheless this type of study sheds light on interpretative processes at stake and the role of the implicit elements introduced by the experimenter.

What consequences can these guided resolutions have on future reasoning? Osman (2007) asked adults to solve a classical WST (abstract items, causal rule). Between a pre-test and a post-test, learning sessions take place: first, the expert attends a heuristic session during which the participant has to make explicit his or her comprehension errors; the expert then guides him or her in the analysis of the problem by means of a falsifying strategy (identification of the role of each card). Through this scaffolding process, the conditional reasoning can change for the expected $\mathrm{p}-\mathrm{q}$ response. Reasoning seems to be modified in depth because the participants who respond quickly also benefit from the procedure, even a day after the learning phase. A logical competence further develops due to the support provided.

The question to be asked then concerns the transfer of the logical competence from a scaffolded situation to an individual one. In Olry-Louis' study (2009), students solve a thematic selection task and a pre-trained peer orientates their attention to each card in turn. The participants then formulate $80 \%$ logical responses when facing a classical selection task, even though it is more abstract. On the contrary, working with a peer who does not focus their attention in this way, the participants are not able to provide conditional responses. Other researchers have studied the adult feedback: when the expert explains the expected logical response in the particular case of abstract tasks, the transfer of reasoning occurs in a variety of selection tasks, either thematic or abstract (Klaczynski 1993; Klaczynski, Gelfand and Reese 1989; Klaczynski and Laipple 1993). Finally, other logical tasks can be used as tools for scaffolding in order to 
enhance conditional reasoning. According to Overton, Byrnes and O'Brien (1985), evidencing contradictions in an inductive reasoning task enables children as young as 12 to subsequently achieve logical deductions in selection tasks.

The scaffolding process remains complex. Many aspects still need to be examined in order to understand tutor-novice interactions, in particular adult-child interactions that contribute to the emergence of a conditional competence. Another kind of interaction can explain how collective reasoning can lead the individuals to elaborate and learn reasoning procedures in order to solve the WST: peer interactions.

\section{Peer Interactions and Reasoning}

Analyzing the interactions between untrained participants makes it possible to understand how the individual achieves internal cognitive coordination, which is usually difficult to observe. Socio-cognitive psychology focuses on cognitive processes originating from collective dynamics: collaboration, cooperation, competition... (Dillenbourg 1999). Among these dynamics, peer collaboration has been the topic of few studies on WST. In this kind of collective functioning, the individuals are of a comparable status and level, they work on the same aspects of the task and share a common goal. Studying these interactions makes it possible to comprehend thinking in the case of problems for which none of the subjects have a solution a priori. For Moshman and Geil (1998), when facing WST, adult dyads provide more logical responses than adults who always work alone. This performance cannot be explained by the imitation, nor by the influence of the more capable partner. How then can it be explained that the interaction between individuals benefits reasoning? The constraints of the problem are first modified so that collective work can intervene on two levels of resolution, stated by the dual-process theory: a heuristic system to retrieve information, limited by archaic constraints, and then an analytic resolution system (Evans 1984; Evans and Over 2004; Houdé 2002; Wason and Evans 1975). According to this theory, the general difficulty with WST stems from a heuristic matching bias regardless of age: the individual focuses on the elements of the instruction. According to Augustinova (2008), the interaction between several individuals constructing a shared representation of the problem involves using a greater amount of information as well as facilitating the finding of cues. As a result, the participants use a falsification strategy. Here, the interaction would reinforce the initial heuristic process. As analytic processes (deduction, inferences...) develop with experience during ontogenesis, we may expect that collaborative interactions progressively lead to pool resources (means of reasoning), particularly when formal reasoning comes into the picture. Indeed, Grosset et al. (2004) have observed slight improvements starting from adolescence whenever the task facilitates these analytic processes. All these studies, however, relegate inter-individual processes merely to the role of influence or factor but not as constitutive of the thinking activity.

On taking a closer look, it is possible that interactive dynamics instantiate original modes of reasoning, which the subject can then rely on individually. For example, the theory of socio-cognitive conflict defines cognitive processes that arise from interpersonal functioning and, under specific conditions, fosters their development (Doise, Mugny and Perret-Clermont 1975; Doise and Mugny 1981; Perret-Clermont 1980). Studies on conditional reasoning have seldom adopted this perspective although it is 
likely to shed a new light on existing theories. The studies of Bucciarelli (2007) and Sacco and Bucciarelli (2008) appear as an exception, even though they deal with syllogisms. They embraced the mental models theory (Johnson-Laird 1983), which argues that reasoning occurs through the representation of premises, and that an inference is deemed valid as long as it is not rejected. In the course of development, representations would be 'complexified'; in the WST, children would move from a conjunctive interpretation ( $\mathrm{P} \mathrm{Q})$, to a bi-conditional model ( $\mathrm{P} \mathrm{Q}$ and $-\mathrm{P}-\mathrm{Q}$ ), and to a logical conditional interpretation (P Q; -P -Q; -P Q) (Barrouillet and Lecas 1999; Johnson-Laird, Byrne and Schaeken 1992). The individuals have enduring difficulty in finding contradictory cases, hence the persistence of a bi-conditional representation that seems to make them believe that "if $p$ then $q \ldots$ and conversely if $q$ then $p$ ". According to Bucciarelli (2007) and Sacco and Bucciarelli (2008), interactions effectively foster the construction of mental models in order to solve syllogisms. It is not simply a matter of suggesting different solutions and choosing among them. Indeed, reasoning improves much more when a conflict first appears at a socio-cognitive level (participants interact collectively and give different responses) then at a cognitive level (isolated participants choose in a panel of responses), rather than in the reverse order of the individual cognitive conflict first, followed by the socio-cognitive conflict. The previous results give an idea of the relevance of the socio-cognitive paradigm in the study of deductive reasoning. Faithful to the Vygotskian assumption, they suggest that collective reasoning precedes and sustains individual reasoning. Nevertheless, these sociocognitive processes are still poorly known in the case of the selection task. Now tutoring and peer interactions imply a higher order of psychological processes: centering and decentering the points of view, sharing interpretations of the problem content, and dealing with pragmatic aspects embedded into the problem.

\section{Centration and Decentering in Reasoning}

Griggs and Cox (1982) have proposed the problem: "if a person is drinking beer, then the person must be over 19 years of age" (an adult can drink a glass of beer, but does not have to; the child must not drink alcohol, etc....). Very early on, children are capable of reasoning in a logical way (Girotto, Gilly, Blaye and Light 1989; Harris and Nunez 1996). In such a case, the subject does not consider questions about causality but rather the possibility that the rule may be contradicted. This is described as the deontic selection task. Kalish (1998) compares the responses of 3 and 4 year-old children and those of adults resolving conditional problems related to social situations or to a physical causality. As early as 3 and a half years of age, children distinguish social rules from physical rules because the former call upon concepts in terms of deontic logic. However, it is only at around 4 years of age that the child finally takes the perspective of other persons into account, and becomes aware of their intentions and knowledge of the rule, in order to ascertain whether the rule may or should be violated. The deontic versions of the selection task bring correct responses at an early age, particularly with the development of intersubjective competences, and allow the child to suspect social rule violations. This form of problem is then perceived as being non-deterministic and is resolved logically; on the contrary, the classical WST proves to be artificial.

Is reasoning the same when confronted with a deontic problem as when faced with an arbitrary problem? According to the theory of pragmatic reasoning schemas 
(Cheng and Holyoak 1985; Girotto, Light and Colbourn 1988), individuals make inferences according to the perceived context and personal goals, which rely on primary processes (such as linguistic analysis) and secondary pragmatic processes (interpretation and information inferences) (Van der Henst 2002). The cognitive system could include a generalized set of rules that are learned and memorized to suit a range of situations. The obligation and permission schemas are not propositional rules but rather action rules, triggered as a function of experience and context, and depend on reasoning as in the case of distinguishing what is necessary from what is sufficient in performing actions or making predictions. This reasoning mode would be archaic without us knowing whether it is innate or merely precocious (Chater and Oaksford 1996).

The expected subjective utility theory (Manktelow and Over 1991) involves individuals who make choices according to their interest, particularly in the area of costs and benefits. Reasoning seems less systematic than in the previous approach, as it does not result from a specific mental structure. The individual anticipates the consequences of possible behaviors. This is demonstrated by the perspective effect (Manktelow and Over 1991): when confronted with a rule that is interpreted in a biconditional way, there may be a variety of points of view depending on the social position of the participant. Such is the case with the following rule "If you tidy your room (p), you will have permission to go outside (q)". The mother contemplates the possibility that the child will tidy up his room (p) but not go out (-q); the child mostly considers going outside (q) without having to tidy his room (-p). Each point of view is motivated in a social situation, which guides the individual to look for counterexamples, whether it would be in a deontic context (Gigerenzer and Hug 1992; Manktelow and Over 1991) or a nondeontic one (Fairley, Manktelow and Over 1999; Staller, Sloman and Ben-Zeev 2000).

The individual's centration on an actor's perspective in relation to specific interests, can considerably orientate the response. Decentering processes just happen to be central in the socio-cognitive approach. The notion of socio-cognitive conflict (Perret-Clermont and Nicolet 2001) has largely well-documented that peer interactions can lead to an interindividual conflict, which, once it has been internalized by the child, brings him or her to perceive a contradiction; following certain conditions, these dynamics support a coordination and even a restructuring of thought, including formal reasoning (Doise and Mugny 1997). Whereas the theory of pragmatic schemas points to very hypothetical rigid cognitive structures, the theory of socio-cognitive conflict and that of subjective utility imply that the participants take their own position and take specific social perspectives. The socio-cognitive theory goes further as decentering in interactions is likely to provide a basis for the development of reasoning about deontic versions of the selection task in future situations.

\section{Socio-Cognitive Regulations Relying on the Content of the Problem}

Deontic reasoning fosters logical performances according to the social position of the participant (Gigerenzer and Hug 1992), particularly when the problem includes a social contract that requires the detection of the cheaters (Cummins 1996, 2004). Due to the social content of the task, the child quickly adopts a cheater detection strategy and this type of problem is often solved logically as early as 3 years of age. According to the evolutionist social contract theory (Cosmides 1989; Cosmides and Tooby 1992), deontic reasoning has phylogenetic and social origins. Phylogenetic altruistic properties 
of reasoning would imply that problems are perceived in terms of costs and benefits, particularly to exploit in-group resources (Hiraishi and Hasegawa 2001). We will now stress the role of the motives of individuals facing a problem, and generally tied to the meanings and desires attributed to the activity (Nickerson 1998).

It is somewhat difficult to investigate on early hominid behaviours. Equally, the role of social meanings contained in the problem actually given to the participants, is not sufficiently taken into account in order to explain the precocity of deontic reasoning. The meanings attributed in the context are indeed an essential matrix for the ontogenetic construction of knowledge (Bruner 1990). A few socio-cognitive studies offer an explanation that concerns the theory of pragmatic schemas of reasoning (Cheng and Holyoak 1985; Cheng, Holyoak, Nisbett and Oliver 1986) even if they did not rely on the WST. According to the social marking theory (Doise and Mugny 1997; Perret-Clermont and Nicolet 2001; Roux and Gilly 1993), implicit social rules are included in the problem and lead to specific resolution procedures: "new cognitive regulations are achieved in as much as they serve for the establishment or maintenance of a social regulation" (Doise and Mugny 1981, p. 42, our own translation). Several experiments have confirmed this theory regarding logical performances. Using a classical pretest-posttest design, Zhou (2001) experimented how dyads of 5-6 year-old children develop the conservation of lengths and volumes. During the training phase, the children had to sort beads into two comparable groups. When the training involves both a social issue (sweets instead of beads) and the spontaneous implementation of a social procedure (dividing up the objects between the children, each in turn), the children later develop individual logical competences that are transferable to other problems. Social meaning fosters problem solving procedures that participate in the construction of reasoning strategies.

The social marking theory explains developmental trends because the performances are maintained in the post-test, thus indicating an individual cognitive change. Are there social features of the task that would be foundational elements for performance and evolution to occur? There is a lack of data on everyday conditional reasoning of children (Church 2007). One important social feature of the task is related to pragmatic processes involved in the way the task is communicated and interpreted

\section{Pragmatics and Communication Frameworks}

Every experimentation includes a communication between experimenters and participants. Inevitably, the reference languages used by both the participants and researchers in the WST influence the inferences drawn. The conversational rules are integrated early on (Eskritt, Whalen and Lee 2008) and constitute the communicative mode of most of our everyday activities. In these conversations, the logical connector "if" may be exclusive or inclusive depending on the situation. This distinction is implicit for most individuals and is rarely explained to children. On the contrary in logic, "if" is inclusive and is explicitly taught to a restricted number of individuals (logicians, computer scientists, law professionals...).

Thanks to the pragmatic approaches, the selection task is a problem communicated by a researcher, and the participant makes inferences that are set in this conversational context (Politzer 1991). According to the theory of relevance (Sperber, Cara and Girotto 1995), several individuals follow the implicit rules of pragmatic functioning 
and engage in a conversation. In such cases, the individuals trust intuitions of relevance that are dependent on both the communicational context and the content of the problem. In this way, any act of communication is presumed to be relevant by the receiver and everyone assumes that, in principle, information is delivered in the most pertinent way possible. These communication principles operate in an artificial and not very conscious way; the attention is then focused on certain aspects of the problem and thereby influences reasoning. However, these rules of conversation sometimes differ from the enunciative rules of logic. This may explain certain performances on the WST: the participant relies on these conversational rules, generally used in daily life, to understand the experimenter's message. He or she assumes that the instruction is formulated so that the problem can be clearly and unequivocally understood. The subject perceives a silence on the part of the experimenter at the end of the task instruction; and, following rules of conversation, deduces an implicit information assumed to be relevant: "and conversely, if there is a 4, then there is an A". If the experimenter wished the problem to be understood in a conditional way, he or she should explicitly: "If there is an A, then there is a $4 \ldots$ but the reverse is not true". The same instruction takes on the opposite meaning when it is interpreted in terms of formal logic. The speaker's silence indicates that there is no predetermined result in other cases: "if there is a 4, then nothing is to be expected". The same formula can describe a problem in a biconditional manner within usual conversational rules and in a conditional manner within the language of formal logic. Is there any way to avoid such communication phenomena in our experiments?

The notion of relevance applied to the WST (Sperber et al. 1995) is insufficient as it focusses essentially on the rules that govern utterances. In order to assume that certain communication rules must be used as opposed to others, further inferences must be made concerning the whole situation of the interpersonal communication. For example, in order to assume that the task involves a difficulty or a linguistic trick, the subject need to think about the experimenter's intentions. It would not be sufficient to consider this experimenter as devoid of any expectation. It can be useful to refer to the notion of communication contract and in particular of experimental contract (Schubauer-Leoni and Grossen 1993): a system of tacit values and rules that structure the social relations between the experimenter and the participants, and which is governed more particularly by principles of relevance, consistency and influence (Schubauer-Leoni and Ntamakiliro 1994, p. 89). During experimentations with the WST, the particitants seem to have no doubt both about the rule stated or the experimenter's expectations. The experimental contract is binding, thus leaving no room for negotiation of the situational rules between the individuals. On the contrary, in everyday situations, prompted by uncertainties about the communication, the individuals can ask questions and propose hypotheses rather than responses, intentionally intervene in the course of the interaction and negotiate the potential meanings of the situation to ensure a certain intersubjectivity. As remarkably summarized by Schubauer-Leoni and Ntamakiliro (1994): "it is a question of identifying meanings attributed by the student and by the experimenter as a function of the contracts to which each of them is tacitly referring. It is therefore possible, in certain cases, to observe misunderstandings that are essentially due to the non-concomitance of the reference worlds of each of them" (p. 89, our translation). Therefore, the relevance enters into the composition of a larger system of the coconstructed situation. The notion of experimental contract frames the interpretation of 
the individuals' actions from the experimenter's as well as from the participant's point of view, and potentially explains why the problem is perceived differently. In a situation where participants face a WST for which they are asked to reason on their own, with no real card and no instrument, a tacit agreement is shared. The participant supposes that the task does not require objects or tools, and that quick procedures are expected to give a response to an equivocal problem.

As a consequence, a socio-cultural perspective of reasoning about the WST implies to extend the unit of analysis. Moreover, in Vygotsky (2004), cognition relies on mediations, either material or symbolic, which permit individuals to define and creatively solve problems in a temporal perspective, and reorganize their past experiences and develop competencies.

\section{Reframing the Thinking Process with Material and Language Mediations}

How to foster the development of general means to solve a class of problems? Several research focused on how to induce the transfer of deontic reasoning to abstract and causal versions of the selection task. Results are numerous but contradictory. Subtle variations intervene according to the tasks: training with arbitrary selection tasks would later encourage logical responses for thematic tasks but not the reverse (Klaczynski, Gelfand and Reese 1989); training on deontic selection tasks can also foster logical responses in more abstract and arbitrary tasks (Cheng et al. 1986; Light, Blaye, Gilly and Girotto 1989), whereas other studies do not find such an effect (Price and Driscoll 1997). It appears that training with adult feedbacks in a causal thematic task would foster logical responses to an arbitrary task, but training with these feedbacks in a deontic task is less supportive (Klaczynski 1993; Klaczynski and Laipple 1993). Rather than looking for an internal transfer of competence, a socioconstructivist light helps to focus on psychological processes (appropriation, interiorization, exteriorization) related to an individual who is going through situations, taking advantage of diverse potential mediations. As a Vygotskyan approach, the situated cognition theory (Lave and Wenger 1991) postulates that knowledge is never de-contextualized, but always contextualized and connected with past or future situations. Therefore, reasoning is a sufficiently reduced and flexible form of thought that can be adapted to multiple experiences. The issue is not so much to find a common response to a class of problems, but to develop mediations, either material or symbolic, and to adjust their flexibility in order to solve future problems. In this section, we analyze the role of objects in their material aspects and in their cultural ones, the role of material tools, and that of language as an internalized tool.

\section{The Form of the Problem and the Material Context: "Redealing the Cards"}

In many studies about the selection task, the information contained in the cards influences the response. Actually, the props (material characteristics of the task) and participant's practices are relatively neglected. Do the artifacts that make up the selection task orientate and explain cognitive procedures? In the WST, each of the four cards has a distinct role according to propositional logic: affirmation or denial of the antecedent, affirmation or denial of the consequent. This scenario is not common in 
everyday situations (Nickerson 1998, p. 185). When individuals are confronted with the following statement: "if you encounter a rabid dog, call the following number", it makes no sense to any individual in that circumstance to pose the question of what will become of dogs that are not rabid, and which animals would be taken to the vet. Since WST types of problems are not very common, it is unnecessary to expect a quick resolution. The Reduced Array Selection Task (RAST), a limited version of the WST, consists in proposing consequents only. With this task, presented in deontic form, 3 to 5 year old children produce logical responses (Cummins 1996; Girotto et al. 1989); adults do the same with a deontic or even with an abstract format (Oaksford, Chater, Grainger and Larkin 1997; Wason and Green 1984). This modification of the task could possibly modify the attention on certain aspects of the problem.

The issue at hand concerns not only attentional constraints but also action constraints. Having an ecological view implies studying how individuals actively organize logical reasoning by relying on a precise context. The scope of the problem could be better ascertained by systematically varying the context rather than only the content of the cards. Vallée-Tourangeau and Krüsi Penney (2005) have shown that for Wason's 2-4-6 task (1960), presenting a die implies real manipulations on a restricted number of values and thus modifies inductive reasoning.

In another form, the task could be presented as follows: "Laid out cards are: $E, A, G$, $3,3, \mathrm{~K}, \mathrm{~A}, 7, \mathrm{Z}, 8$. The rule says: "if there is an A on one side of the card, then there is a 3 on the other side". Here, the individuals can question whether the rule holds true for certain cards or for a category of cards, and thus mobilizes other cognitive processes, even though the logical structure of the problem is the same. Manktelow, Sutherland and Over (1995) have carried out such an experiment with the Large Array Selection Task (LAST), in a deontic form to study perspective effects. They invite us to explore such a material change with an abstract selection task (p. 208). An in-depth analysis of the responses and procedures is necessary like making hypotheses, manipulating, generalizing, classifying... Indeed, the material context modifies the praxeological universe. The classical WST (with a strict reduction of the material context) prevents the observation of all such actions and reasoning.

For Vygotsky (1994), the context plays a role in the development of the individual but only as function of the previous knowledge and ability to act within the given context, and not exclusively as a function of the external properties of this context at hand. The goals of the task (i.e. the problem) could be changed, redefined for the participants, engaging them toward other kinds of activity.

\section{Social and Cultural Comprehension of the Material Context}

Context rarely influences reasoning through purely external modalities. Social representations can mix up the concrete aspects of the problem. For instance, Manktelow et al. (1995) proposed a selection task where the rule invites the participants to monitor the risk of contamination on the border of a country. The participants often turned over the "Tropical countries" cards because they already knew that cholera is likely to be found in such countries. Reasoning in context also implies choosing a selection of cards. Since the individual does not know a priori on the basis of the present data the solution to the problem, some uncertainties demand that he or she makes a suitable choice. Decision making and seeking counter-examples inspire the probabilistic 
approach (Oaksford and Chater 1994, 2009; Schroyens and Schaeken 2003): the decision is developed from probabilistic inferences rather than from the construction of representations. Therefore, if A and 4 are specific letter and number cases, in spite of their ignorance about the set of cards, the subject assumes that these specifics are rare and are likely to optimally reduce uncertainty. According to this approach, the individuals build a correct representation of the problem but, because of uncertainties, they will not merely follow its logical implications. Few developmental studies are engaged in this approach, although it proposes that experience involves cognitive reorganizations. A developmental model of the probabilist theory as applied to the WST, including both biological and enculturational aspects, is currently lacking (Straubinger, Cokely and Stevens 2009). Markovits and Thompson (2008) only show that, probabilistic rather than intuitive judgments, establish a basis for specific reasoning implemented early on in the course of ontogenesis, and that the explicit search for counterexamples would develop later in time, generally after the age of 6 . Conditional reasoning relating to data that is not meaningful, would be restrained by quick, probabilistic inferences, whereas meaningful material would elicit other cognitive processes. The same conclusions are drawn about the conjunctive probability judgment. The probability that two events occur conjunctively regularly leads to an overestimation of the probability of one of these two events. This overestimation decreases at a young age whenever the problem is presented via colored boxes (Fisk, Bury and Holden 2006), whereas, if the objects involve social meanings, overestimation is reinforced with age (Davidson 1995). For instance, an edelweiss will most probably be placed in Switzerland than in Europe. Because individuals make judgments according to representativeness heuristics (Tversky and Kahneman 1983), the least probable event calls for focusing the attention on more consistent and precise representations. The individuals learn to make estimations but not without the increasing intervention of social representations. All of these studies suggest then that our judgments and representations of reality are mediated by cultural rationales that have to be analyzed in the case of the selection task.

\section{Objects can be Integrated into the Cognitive System: Instrumental Mediations}

When facing an arduous problem, individuals can intentionally alter the context in order to overcome certain constraints and regulate their cognitive potentialities. In the Vygotskyan approach, technical instruments can be used as mediators of cognition. They support individual capabilities but also create new possibilities for the resolution. The 'unit of analysis' is thus extended to artifacts (Stetsenko 2005). The case in which the individual reasons with few external instruments (as it is regularly assumed in the selection tasks) constitutes a specific situation, which does not open up to an unbiased nor a better understanding of cognition. If having a representation of the problem is essential, then the external representation activity should play an important place in the resolution. The use of writing (on a paper, on a computer...) could improve conditional reasoning: it forces one to use signifiers, enables to constitute an external memory, to practically test and transform representations, and then to regulate practices. Bauer and Johnson-Laird (1993) already demonstrated this in relation to logical reasoning and disjunctions: the participants give better responses when they have to solve the problems with a diagram rather than verbally. In fact, material representations may make the response possibilities salient and may limit erroneous choices. They eventually 
support the search for alternative responses, which is important for conditional reasoning (Cummins 2004). Such considerations open new avenues for developmental analyses, if we study how individuals then change their tools.

Logic as a formal discipline is a conceptualization originating from a historical process. An isolated subject can hardly discover its rules via his or her own confrontation with the reality. The abstraction of the logicians results from a learning process hinged more particularly on reasoning capabilities supported by tools. Among the tools used, symbolic practices give shape to concepts and enable to manipulate them, such as truth tables or Euler circles. These tools guide thought and generate the very analysis of the problem. From a developmental viewpoint, the problem is to study how the novice use these tools in comparison with the logician. Instead of cognitive processes operating in a propositional universe, two processes related to instrumental practices shed light on the ontogenesis of reasoning on the WST: internalization and appropriation. According to Vygotsky (1978), many tools have already been made in the culture, and the individual does not need to reinvent tools but to appropriate them. Rather than a simple transmission of instrumental competence, the appropriation process points to a re-elaboration that responds to specific uses depending on the subject and on the context. Internalization consists in mentally reconstructing an external tool, which, at first, the individual concretely used to realize the activity.

One study illustrates the role of tools in the development of reasoning skills applied to the selection task. Van der Pal and Eysink (1999) asked students to individually solve variants of the WST. After a pre-test, the participants solved six reasoning tasks using a computer application. One part of the program featured a 3D representation of the problem, and the other part offered statements about the problem in natural language. The software provided feedbacks on the accuracy of the response. Only the participants using both graphical and textual spaces, improved their post-test logical resolution of the WST, and this effect was increased a week later. The participants must appropriate an explanation on conditional logic and two different representational spaces. One could then assume that some students internally mobilize these representations successfully when they have to solve again the problem with no instrumental context. Being able to reason in an autonomous manner could rely on instrumental practices that later become internal tools thereby giving the illusion of an endogenous development. The art of the logician often consists in having internalized these mediations and being able to operate mentally, which facilitates the development of transferable, thus apparently general, skills. Language activities also follow this analysis.

\section{Language in Use: Multiple Functions of Language for Thinking}

Language has cognitive consequences as it can drastically alter representations and reasoning processes. For instance, when starting to use "if" in their conversations with adults, 23 to 63 months old toddlers start to make conditional inferences (Scholnick and Wing 1995). Language also intervenes in classification processes. Words and concepts are produced in part from cultural cut-outs of reality as well as from an appropriation on the part of the individual. Therefore, some researchers advocated that the familiar nature of the content play an important role in certain variants of the WST (Johnson-Laird, Legrenzi and Legrenzi 1972; Wason and Shapiro 1971), whereas others such as Ward, Byrnes and Overton (1990), postulate that the semantic 
organization of cognition determines relations of inclusion and thus explains the effect of the content better than familiarity.

Why don't the participants use these functions of language to solve the WST? It could be that the majority of the participants, under WST conditions, are lacking the need of a specific language for its resolution. Words and concept are intimately linked in Vygotsky's theory: "The retardation in the development of logical reasoning and in the formation of concepts is due here entirely to the fact that children have not sufficiently mastered the language, the principal weapon of logical reasoning and the formation of concepts" (Vygotsky 1929, p. 417). His theory of word meaning development could enable us to understand how the individual using everyday concepts ("if" in a biconditional manner) to a more scientific one ("if" as the marker of logical implication). Blaye, Ackerman and Light (1999) attempt an explanation for the varying performances of individuals in the selection tasks: the ability to use deontic reasoning seems to depend on relatively ordinary contexts, which is not the case in formal logic structures, as they pertain to very specific context, requiring a technical language (computer science, mathematics...). These authors particularly recommend the study of the development of necessity in the deontic and logical senses of the word.

However, rather than considering language as a provider of already made concepts, the question at hand concerns semiotic uses of language in situ, i.e., the way individuals make use of it to solve conditional problems. Language becomes a tool because the individual has learned its various specific uses, and masters other types of language besides natural language. It then turns out to be useful even in case of few interpersonal interactions. What specific functions does it have in the resolution of the task? It can serve argumentation, questioning, classification... purposes. There is a large array of regulatory functions, potentially helping to solve the WST. Two functions of language illustrate this: explanation and argumentation.

The ability to exteriorize supports the grasp of consciousness. In thinking-aloud protocols, the participants have to verbalize their resolution procedure when confronted with selection tasks (Lucas and Ball 2005). This verbalization, such as in the methodology of Wason himself (see Wason 1977), can be used by researchers in order to gain access to cognitive processes that are assumed to be independent, although the cognitive consequences of this change of task are rarely discussed. According to Green (1995), on the other hand, externalization allows the participants to identify counterexamples, to relate them to the cards and to make logical selections. Similarly, Trognon (1993) and Laux et al. (2008) have used interlocutory logic to present the implications of externalization through conversation: formulation trials transform the participants' understanding of the problem presented, revealing possilibities of cognitive maneuvers; one participant finally doubts, explains and reorients the dyad to a logical reasoning. Through conversation, externalization processes facilitate the mobilization of new strategies.

Another function of language is to solve problems through argumentation processes (Mercier and Sperber 2011; Muller Mirza, Perret-Clermont, Tartas and Iannaccone 2009; Pontecorvo and Arcidiacono 2010). Argumentation implies making inferences that are likely to support conditional reasoning. Thompson, Evans and Handley (2005) examined social situations where conditional propositions were produced with the intention of persuading or dissuading someone: the participants adopt a deductive reasoning more easily when they produce the conditional rule for the argumentation 
themselves as opposed to when they solely were given the rule by an experimenter. This type of social functioning is a good illustration of the fact that individuals employ particular uses of language to think and reason logically in certain situations. In this case, language is no longer purely an enonciative context of thought nor is it merely a communication tool, but a component that individuals can actively set up to shape reasoning, when our methodologies enable them to be proactive.

From a situated perspective (Lave and Wenger 1991), formal conditional reasoning is not a universal and necessary adaptation to any and all environments; it is the product of cultural processes in which the individual may possibly come across specific problems situated in a propositional world. Logical reasoning situations require formalized cultural tools (such as formal logic language) that are different from the ones used in everyday situations (such as common language), and possibly involve other decision and reasoning processes. Before an individual can legitimately rely on any type of language, he or she must internalize its specific functions and have the instrumental competence to employ these functions. It is necessary to internalize such specific functions to be able to use them in different situations, that is to say to transfer them from situation to situation (Guberman and Greenfield 1991). As regards to conditional reasoning, the internalization and externalization processes that enable to analyze more clearly this evolution are still obscure. Van der Pal and Eysink (1999) research study can be mentioned again, as it shows how a logical language is taught to individuals who appropriate it with the help of a technical device and are later able to solve conditional problems, although they are no longer explicitly instructed to use this language. In the post-tests, it is supposed that individuals still use language internally and rely on past instrumental means. The aim of future research may be to study how individuals use language functions collectively and internalize them or reuse them in new situations.

\section{Research Perspectives}

Hereafter, the reader would find a list of statements in order to empirically study conditional reasoning and to draw a more accurate picture of certain culturalhistorical issues about the selection task. Certain material and social circumstances that remains to be scrutinized (scaffolding, division of work, opposing reasons in competition in argumentation, collaboration, instrumental settings...) could lead the individual to develop strategies and may imply fundamental restructuring in conditional reasoning. The development of conditional reasoning on the WST is contextually bound, and scholars would be inspired to change the material and functional context of the task (instruments, meanings...) and to combine them in a temporal perspective to explore possible learning effects.

The classical works on the selection task shows a variety of individual performances, but often presents a mechanism that is internal to the individual. Relying on a sociocognitive perspective leads us to examine individuals in situations of resolution of the WST and allows us to point the necessity to situate the work of thinking developed by individuals in problem solving. In order to clarify the contribution of this article we proposed a figure (see Fig. 1) adapted from the theory of activity (Engeström 2005; Leontiev 1978) which enables one to envision an expanded 


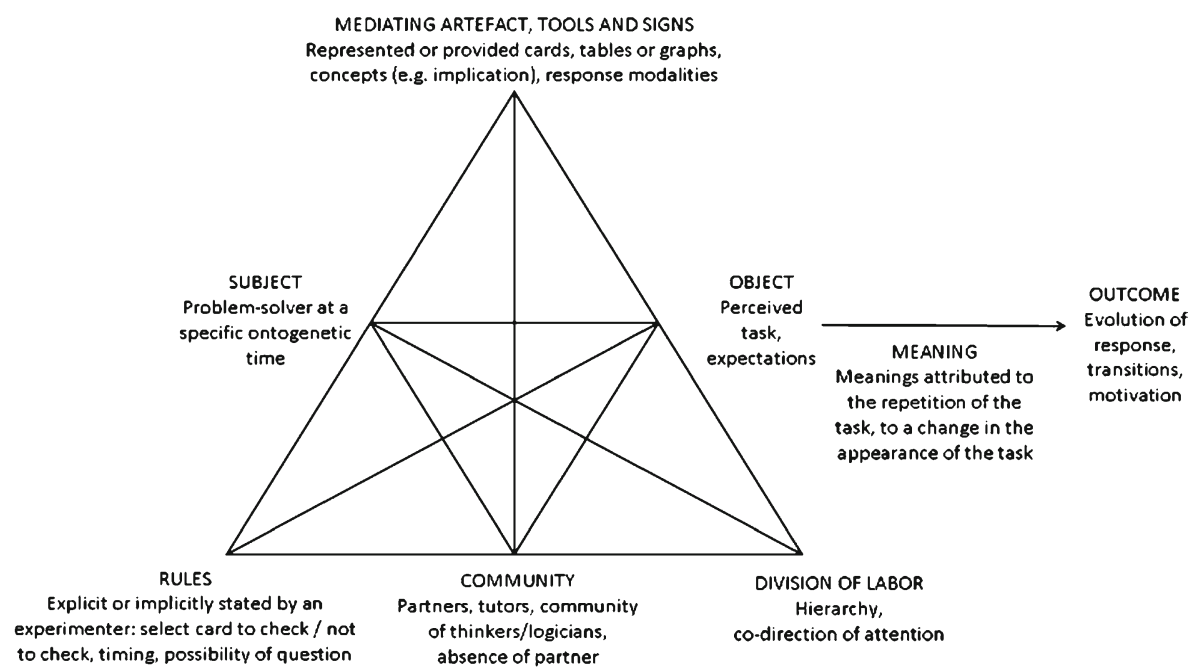

Fig. 1 The activity system in a specific setting and reasoning change about the selection task (adapted from Engeström 2005, p. 61)

cognitive system, in such a way that conditional reasoning would not be a mere abstract capability solely observed in a socially and materially poor environment. Indeed, one could believe that analyzing mental processes is more complicated because of a multitude of external and secondary constraints (i.e. objects, instructions, partners, etc.). However, what is at stake is a change in the unit of analysis: a cognitive system that is not only limited to an intraindividual level of analysis, but combines intra- and inter-subjective levels into certain socio-cognitive regulations of the activity. The idea of cultural mediation indicates that it is not only a matter of accumulating contextual informations in an individual cognitive system, but also a matter of studying how the individual sometimes relies on various tool functions (enabled by various semiotic structures of the tools) to regulate the whole activity. It is no longer a question of expressing a thought through language, but of creating an argumentative dynamics to integrate contradictory ideas and re-presenting the problem to one's self. It is not a matter of multiplying individual thoughts, but of establishing collective processes that lead to a specific organization of the work. The next figure (see Fig. 1), inspired from Engeström (2005), particularly highlights that the subject-task relation is embedded in a whole system including the interindividual dimension (subject-object, rules, community and division of labor) and the mediations of material and symbolic tools (subject-object, mediating artifacts, tools and signs). On this figure, two essential elements are remaining which defines cognitive change: meaning and outcomes.

We proposed then two perspectives of research focusing on two main aspects outlined in the figure: the importance of meaning-making processes and the necessity to reconsider cognitive change through a socio-cultural approach. Both perspectives lead us to propositions in terms of methodological implications.

A first perspective consists in taking better into account the meanings attributed by the participants into the solving activity. For example, the content of the task, the communication intentions of the researcher, the device implemented (lack of tools, presence of partners, etc....) and finally the situation as it is perceived by the 
participants. The studies using the WST have already brought invaluable elements to the role of content and contextual effects. The studies on relevance are in the same vein: they reposition the researcher inside a system. The epigenetic development of conditional reasoning is studied into a system designed by the research, and which, in turn, the participants analyze and interpret in order to understand the task. In the footsteps of Valsiner (2007), researchers could propose situations that imply motives for the participants, i.e. situations to which they adhere because they find them to be meaningful or offering a personal challenge. The problem is constructed by the subject within a certain social and material framework that he or she actively participates in.

A second perspective is related to cognitive changes. Numerous studies have shown the importance of learning processes for the development of conditional reasoning (e.g. Houdé and Tzourio-Mazoyer 2003; Olry-Louis 2009; Osman 2007; Overton et al. 1987). From a socio-constructivist perspective, we try to describe the heterogeneity of procedures in relations with the plurality of situations. Several processes are possible when individuals run into such a problem. Transfer is one single and internal adaptation. There are other possibilities as taking advantage of a collective work, looking for cultural resources, modifying the task, elaborating on the meanings and identity, etc.... A simple exploration reveals that some participants are in search of a rationality behind the letters and numbers of the cards of the WST. By logicians's standards, these strategies would be unexpected, but have to be understood by psychologists. Evolution in time implies the possibility for the subject to make adjustments also refering to "unrational" problems. Zittoun and Perret-Clermont (2009) indicate the importance to distinguish "transfer" and "transition" processes. The notion of transition implies that individuals face, interpret and react to ruptures in their past experiences. Therefore, this notion extends our understanding of the subjects, not only situated into a physical objective here-and-now context but also in their social and cultural contexts, connected to the individual's past experiences (Zittoun 2008). The evolution of a participant confronted several times to a selection task is challenging to investigate (especially if an experimenter, perceived as an expert, is asking someone to solve the same problem again without any feedback). Moreover, the notion of "transfer" is not always an internal cognitive transfer but also the creative re-use of social components from context to context (Zittoun and Perret-Clermont 2009). This research path avoids limiting a priori the future cognitive possibilities of human beings based on current responses in limited contexts. Its prospective scope invites us to consider how actions and thinking can be modified, particularly via educational systems.

To conclude with methodological suggestions, detecting the accuracy of the responses or reasoning errors would seem somewhat simplistic. In numerous studies, reasoning is inferred from frequencies of final responses, and effective procedures are neglected. It would be convenient to study the trajectories of the responses and problem solving procedures from situation to situation. To this end, several tasks are necessary to diversify the semantic contents, the logical instances proposed, the contexts, and the meanings attributed by the participants. Due to the complexity of these research perspectives, we will evoke several empirical practices. The first set comprises ethnographic methodologies: having a panorama of conditional reasoning situations remains a prerequisite to assess the validity of studies on this type of reasoning. Empirical reviews, like Nickerson's study (1998), are also of invaluable help in that way. Other qualitative analyses, as observations or interviews, possibly implemented in classical 
experiments, should take into account the meanings attributed by the participants to the task. Thus, the community should better analyze the common heterogeneity of the illogical responses, as well as better understand why few people give the logical response. Another methodological suggestion is to extend the scope on the activity processes. This dimension is often removed by the researcher who wants to present a neat, uncluttered research plan, albeit artificial, where the task presented (choosing and saying to turn around cards with symbols at the request of a stranger) would replace usual activities (such as the way a customs officer decides to control passengers or not). Relying exclusively on pre-test/post-test assessments does not allow to enter in the process of cognitive change as suggested Furberg and Arnseth (2009) in their sociocultural approach of conceptual change. Finally, a microgenetic (Saada-Robert and Balslev 2006) or a micro-historical approach (Perret-Clermont and Schubauer-Leoni 1981; Tartas, Baucal and Perret-Clermont 2010; Tartas and Perret-Clermont 2012) could be appropriate methods to drop the research anchor further down into the depths of conditional thinking. Inhelder's work is pertinent in this regard although it focuses on an ontogenetic construction of cognition (Inhelder and Piaget 1958; Inhelder and Cellérier 1992). As an example of study, in order to integrate a social and material extension of the WST, we suggest to use an abstract selection task with many cards where the participants have to collaborate to solve the task. This methodological adjustment could lead the participants to make more inferences, to argue with several standpoints and to observe contradictions, i.e. meet a true problem. All of these levels of analyses promote a more original perspective to understand the development of reasoning on the selection task, thus considering the importance of learning situations.

Acknowledgments We are very grateful to Professor Anne-Nelly Perret-Clermont and Professor Francesco Arcidiacono for their constructive and valuable comments.

\section{References}

Augustinova, M. (2008). Falsification cueing in collective reasoning: Example of the Wason selection task. European Journal of Social Psychology, 38, 1-16.

Barrouillet, P., \& Lecas, J. F. (1999). Mental models in conditional reasoning and working memory. Thinking \& Reasoning, 5(4), 289-302.

Bauer, M. I., \& Johnson-Laird, P. N. (1993). How diagrams can improve reasoning. Psychological Science, 4, $372-378$.

Blaye, A., Ackerman, E., \& Light, P. (1999). The relevance of relevance in children's cognition. In J. Bliss, P. Light, \& R. Saljö (Eds.), Learning sites: social and technological contexts for learning (pp. 120-131). Amsterdam: Pergamon.

Brossard, M. (1999). Apprentissage et développement: tensions dans la zone proximale de développement. In Y. Clot (Ed.), Avec Vygotski (pp. 209-220). Paris: La Dispute.

Bruner, J. S. (1983). Le développement de l'enfant: Savoir faire, savoir dire. Paris: P.U.F.

Bruner, J. S. (1990). Acts of Meaning. Cambridge, MA: Harvard University Press.

Bucciarelli, M. (2007). How the construction of mental models improves learning. Mind \& Society, $1(6), 67-89$.

Chater, N., \& Oaksford, M. (1996). Deontic reasoning, modules and innateness: A second look. Mind \& Language, 11, 191-202.

Cheng, P. W., \& Holyoak, K. (1985). Pragmatic reasoning schemas. Cognitive Psychology, 17, 391-416.

Cheng, P. W., Holyoak, K. J., Nisbett, R. E., \& Oliver, L. M. (1986). Pragmatic versus syntactic approaches to training deductive reasoning. Cognitive Psychology, 18, 293-328. 
Church, A. (2007, July). Threats in children's disputes: Learning conditionality. Paper presented at the 10th International Pragmatics Conference, Göteborg, Sweden.

Cosmides, L. (1989). The logic of social exchange: Has natural selection shaped how humans reason? Studies with the Wason selection task. Cognition, 31, 187-276.

Cosmides, L., \& Tooby, J. (1992). Cognitive adaptations for social exchange. In J. Barkow, L. Cosmides, \& J. Tooby (Eds.), The adapted mind: Evolutionary psychology and the generation of culture (pp. 163-228). New York: Oxford University Press.

Cummins, D. D. (1996). Evidence of deontic reasoning in 3- and 4-year-old children. Memory \& Cognition, $24,823-829$.

Cummins, D. D. (2004). The evolution of reasoning. In J. P. Leighton \& R. J. Sternberg (Eds.), The Nature of Reasoning (pp. 339-374). Cambridge: Cambridge University Press.

Davidson, D. (1995). The representativeness heuristic and the conjunction fallacy effect in children's decision making. Merrill Palmer Quarterly, 41(3), 328-346.

De Neys, W., \& Everaerts, D. (2008). Developmental trends in everyday conditional reasoning: the retrieval and inhibition interplay. Journal of Experimental Child Psychology, 100, 252-263.

Dillenbourg, P. (1999). What do you mean by 'collaborative learning'? In P. Dillenbourg (Ed.), Collaborativelearning: Cognitive and Computational Approaches (pp. 1-19). Oxford: Elsevier.

Doise, W., \& Mugny, G. (1981). Le développement social de l’intelligence. Paris: InterEditions.

Doise, W., \& Mugny, G. (1997). Le raisonnement formel: nouvelles perspectives. In W. Doise \& G. Mugny (Eds.), Psychologie sociale et développement cognitif (pp. 191-206). Paris: Armand Colin.

Doise, W., Mugny, G., \& Perret-Clermont, A.-N. (1975). Social interaction and the development of cognitive operations. European Journal of Social Psychology, 5(3), 367-383.

Engeström, Y. (2005). Developmental work research: Expanding activity theory in practice. Berlin: Lehmanns Media.

Eskritt, M., Whalen, J., \& Lee, K. (2008). Preschoolers can recognize violations of the Gricean maxims. British Journal of Developmental Psychology, 26, 435-443.

Evans, J. S. B. T. (1984). Heuristic and analytic processes in reasoning. British Journal of Psychology, 75, 451-468.

Evans, J. S. B. T., \& Over, D. E. (2004). If. Oxford: Oxford University Press.

Faiciuc, L. E. (2008). Are there reasons to challenge a symbolic computationalist approach in explaining deductive reasoning? Integrative Psychological and Behavioral Science, 42(2), 212-218.

Fairley, N., Manktelow, K. I., \& Over, D. E. (1999). Necessity, sufficiency and perspective effects in causal conditional reasoning. The Quarterly Journal of Experimental Psychology Section A: Human Experimental Psychology, 52(3), 771-790.

Fisk, J. E., Bury, A. S., \& Holden, R. (2006). Reasoning about complex probabilistic concepts in childhood. Scandinavian Journal of Psychology, 47(6), 497-504.

Furberg, A., \& Arnseth, H. A. (2009). The importance of socio-cultural context for understanding students' meaning making in the study of genetics. Cultural Studies of Science Education, 4, 211-219.

Gigerenzer, G., \& Hug, K. (1992). Domain-specific reasoning: social contracts, cheating and perspective change. Cognition, 43, 127-171.

Girotto, V., Light, P., \& Colbourn, C. (1988). Pragmatic schemas and conditional reasoning in children. Quartely Journal of Experimental Psychology, 40A, 469-482.

Girotto, V., Gilly, M., Blaye, A., \& Light, P. (1989). Children's performance in the selection task: plausibility and familiarity. British Journal of Psychology, 80, 79-95.

Granott, N. (1998). Unit of analysis in transit: From the individual's knowledge to the ensemble process. Mind, Culture, and Activity, 5, 42-66.

Green, D. W. (1995). Externalization, Counter-examples, and the Abstract selection task. The Quarterly Journal of Experimental Psychology, 48A(2), 424 446.

Griggs, R. A., \& Cox, J. R. (1982). The elusive thematics material effect in Wason's selection task. British Journal of Psychology, 73, 407-420.

Grossen, M. (2010). Interaction analysis and psychology: a dialogical perspective. Integrative Psychological and Behavioral Science, 44(1), 1-22.

Grosset, N., Barrouillet, P., \& Misuraca, R. (2004). Développement du raisonnement conditionnel et tâche de sélection de Wason. L'Année Psychologique, 104, 51-81.

Guberman, S. R., \& Greenfield, P. M. (1991). Learning and transfer in everyday cognition. Cognitive Development, 6(3), 233-260.

Harris, P. L., \& Núñez, M. (1996). Understanding of permission rules by pre-school children. Child Development, 67, 1572-1591. 
Hiraishi, K., \& Hasegawa, T. (2001). Sharing-rule and detection of free-riders in cooperative groups: Evolutionarily important deontic reasoning in the Wason Selection task. Thinking and Reasoning, 7(3), 255-294.

Houdé, O. (2002). Le raisonnement logique. In O. Houdé, B. Mazoyer, \& N. Tzourio-Mazoyer (Eds.), Cerveau et psychologie (pp. 547-582). Paris: PUF.

Houdé, O., \& Tzourio-Mazoyer, N. (2003). Neural foundations of logical and mathematical cognition. Nature Reviews Neuroscience, 4, 507-514.

Inhelder, B., \& Cellérier, G. (Eds.). (1992). Le cheminement des découvertes de l'enfant. Neuchâtel: Delachaux et Niestlé.

Inhelder, B., \& Piaget, J. (1958). The growth of logical thinking from childhood to adolescence. New York: Basic Books.

Johnson-Laird, P. N. (1983). Mental Models: Towards a Cognitive Science of Language, Inference, and Consciousness. Cambridge, MA: Harvard University Press.

Johnson-Laird, P. N., Legrenzi, P., \& Legrenzi, M. S. (1972). Reasoning and a sense of reality. British Journal of Psychology, 63, 395-400.

Johnson-Laird, P. N., Byrne, R. M. J., \& Schaeken, W. (1992). Propositional reasoning by model. Psychological Review, 99, 418-439.

Kalish, C. (1998). Reasons and causes: Children's understanding of conformity to social rules and physical laws. Child Development, 69(3), 706-720.

Klaczynski, P. A. (1993). Reasoning schema effects on adolescent rule acquisition and transfer. Journal of Educational Psychology, 85(4), 679-692.

Klaczynski, P. A., \& Laipple, J. S. (1993). Role of content domain, logic training, and IQ in rule acquisition and transfer. Journal of Experimental Psychology: Learning, Memory, and Cognition, 19(3), 653-672.

Klaczynski, P. A., Gelfand, H., \& Reese, H. W. (1989). Transfer of conditional reasoning: Effects of explanations and initial problem types. Memory and Cognition, 17, 208-220.

Klaczynski, P. A., Schuneman, M. J., \& Daniel, D. B. (2004). Theories of conditional reasoning: A developmental Examination of Competing Hypotheses. Developmental Psychology, 40, 559-571.

Laux, J., Trognon, A., \& Batt, M. (2008). Clinique des raisonnements collectifs accomplis par des dyades réussissant la tâche de sélection de Wason dans sa version abstraite. Psychologie française, 53(3), 375-397.

Lave, J., \& Wenger, E. (1991). Situated learning. Legitimate peripheral participation. Cambridge: Cambridge University Press.

Leontiev, A. N. (1978). Activity, consciousness, and personality. Englewood Cliffs, NJ: Prentice-Hall.

Light, P., Blaye, A., Gilly, M., \& Girotto, V. (1989). Pragmatic schemas and logical reasoning in 6 to 8-yearold children. Cognitive Development, 4, 49-64.

Lucas, E. J., \& Ball, L. J. (2005). Think-aloud protocols and the selection task: Evidence for relevance effects and rationalisation processes. Thinking and Reasoning, 11, 35-66.

Manktelow, K. I., \& Over, D. E. (1991). Social rules and utilities in reasoning with deontic conditionals. Cognition, 39, 85-105.

Manktelow, K. I., Sutherland, E. J., \& Over, D. E. (1995). Probabilistic factors in deontic reasoning. Thinking and Reasoning, 1, 201-220.

Markovits, H., \& Thompson, V. (2008). Different developmental patterns of simple deductive and probabilistic inferential reasoning. Memory and Cognition, 36(6), 1066-1078.

Matusov, E. (1998). When solo activity is not privileged: The participation and internalization models of development. Human Development, 41, 326-349.

Matusov, E. (2007). In search of "the appropriate" unit of analysis for sociocultural research. Culture \& Psychology, 13(3), 307-333.

Mercier, H., \& Sperber, D. (2011). Why do humans reason? Arguments for an argumentative theory. Behavioral and Brain Sciences, 34, 57-111.

Moshman, D., \& Geil, M. (1998). Collaborative reasoning: Evidence for collective rationality. Thinking and Reasoning, 4(3), 231-248.

Muller Mirza, N., Perret-Clermont, A.-N., Tartas, V., \& Iannaccone, A. (2009). Psychosocial processes in argumentation. In N. Muller Mirza \& A.-N. Perret-Clermont (Eds.), Argumentation and education (pp. 67-90). New-York: Springer.

Müller, U., Overton, W. F., \& Reene, K. (2001). Development of conditional reasoning: A longitudinal study. Journal of Cognition and Development, 2, 27-49.

Nickerson, R. S. (1998). Confirmation Bias: A Ubiquitous Phenomenon in Many Guises. Review of General Psychology, 2(2), 175-220.

Oaksford, M., \& Chater, N. (1994). A rational analysis of the selection task as optimal data selection. Psychological Review, 101, 608-631. 
Oaksford, M., \& Chater, N. (2009). Precis of Bayesian rationality: The probabilistic approach to human reasoning. Behavioral and Brain Sciences, 32, 69-84.

Oaksford, M., Chater, N., Grainger, B., \& Larkin, J. (1997). Optimal Data Selection in the Reduced Array Selection Task (RAST). Journal of Experimental Psychology: Learning, Memory, and Cognition, 23, 441-458.

Oberlé, D., Drozda-Senkowska, E., \& Quémy, F. (2002). Lorsque la discussion de groupe doit aboutir à une solution consensuelle de la tâche de sélection: polarisation et autres modalités de consensus. Cahiers Internationaux de Psychologie Sociale, 55, 10-25.

Olry-Louis, I. (2009). Effects of different forms of tutor action in a conditional reasoning task: an experimental approach to the tutorial dialogue. European Journal of Psychology of Education, 26, 169-180.

Osman, M. (2007). Can Tutoring Improve Performance on a Reasoning Task Under Deadline Conditions? Memory \& Cognition, 35(2), 342-351.

Overton, W. F., \& Dick, A. S. (2007). A Competence-Procedural and Developmental Approach to Logical Reasoning. In M. J. Roberts (Ed.), Integrating the mind (pp. 332-366). Hove, UK: Psychology Press.

Overton, W. F., Byrnes, J.-P., \& O’Brien, D. P. (1985). Developmental and individual differences in conditional reasoning: The role of contradiction training and cognitive style. Developmental Psychology, 21, 692-701.

Overton, W. F., Ward, S. L., Noveck, I. A., Black, J., \& O’Brien, D. P. (1987). Form and content in the development of deductive reasoning. Developmental Psychology, 23, 22-30.

Perret-Clermont, A.-N. (1980). Social interaction and cognitive development in children. London: Academic Press.

Perret-Clermont, A.-N., \& Nicolet, M. (2001). Interagir et connaître. Enjeux et régulations sociales dans le développement cognitif. Paris: L'Harmattan.

Perret-Clermont, A.-N., \& Schubauer-Leoni, M.-L. (1981). Conflict and cooperation on opportunities for learning. In W. P. Robinson (Ed.), Communication in Development (pp. 203-233). London: Academic Press.

Piaget, J. (1970). L'épistémologie génétique. Paris: PUF.

Politzer, G. (1991). L'informativité des énoncés: contraintes sur le jugement et le raisonnement. Intellectica, 11(1), 111-147.

Pontecorvo, C., \& Arcidiacono, F. (2010). Development of reasoning through arguing in young children. Cultural-Historical Psychology, 4, 19-29.

Price, E. A., \& Driscoll, M. P. (1997). An inquiry into the spontaneous transfer of problem-solving skill. Contemporary Educational Psychology, 22, 472-494.

Rips, L. J. (1994). The psychology of proof: Deductive reasoning in human thinking. Cambridge, MA: MIT Press, Bradford Books.

Roux, J.-P., \& Gilly, M. (1993). Social significance of tasks, routines and pragmatic schemas in distribution activities. European Journal of Social Psychology, 23, 355-371.

Saada-Robert, M., \& Balslev, K. (2006). Les microgenèses situées. Etudes de la transformation des connaissances. Revue Suisse des Sciences de l'Education, 28(3), 487-514.

Sacco, K., \& Bucciarelli, M. (2008). The role of cognitive and socio-cognitive conflict in learning to reason. Mind \& Society, 7(1), 1-19.

Scholnick, E. K., \& Wing, C. S. (1995). Logic in conversation: Comparative studies of deduction in children and adults. Cognitive Development, 10, 319-345.

Schroyens, W., \& Schaeken, W. (2003). A critique of Oaksford, Chater and Larkin's (2000) conditional probability model of conditional reasoning. Journal of Experimental Psychology: Learning, Memory, and Cognition, 29, 140-149.

Schubauer-Leoni, M.-L., \& Grossen, M. (1993). Negotiating the meaning of questions in didactic and experimental contracts. European Journal of Psychology of Education, 8(4), 451-471.

Schubauer-Leoni, M. L., \& Ntamakiliro, C. (1994). La construction de réponses à des problèmes impossibles. Revue des Sciences de l'Éducation, 20, 87-113.

Smorti, A. (2008). Everyday Life Reasoning, Possible Worlds and Cultural Processes. Integrative Psychological and Behavioral Science, 42(2), 224-232.

Sperber, D., Cara, F., \& Girotto, V. (1995). Relevance theory explains the selection task. Cognition, 57, 31-95.

Staller, A., Sloman, A., \& Ben-Zeev, T. (2000). Perspective effects in non-deontic versions of the Wason selection task. Memory \& Cognition, 28, 396-405.

Stenning, K., \& van Lambalgen, M. (2001). Semantics as a foundation for psychology: A case study of Wason's selection task. Journal of Logic, Language and Information, 10, 273-317.

Stenning, K., \& van Lambalgen, M. (2004). A little logic goes a long way: basing experiment on semantic theory in the cognitive science of conditional reasoning. Cognitive Science, 28(4), 481-529. 
Stetsenko, A. (2005). Activity as object-related: Resolving the dichotomy of individual and collective planes of activity. Mind, Culture, and Activity, 12, 70-88.

Straubinger, N., Cokely, E. T., \& Stevens, J. R. (2009). The dynamics of development: Challenges for Bayesian rationality. Behavioral and Brain Sciences, 32, 103-104.

Tartas, V., \& Perret-Clermont, A.-N. (2012). Faire avec autrui: une situation pour comprendre le développement. In Y. Clot (Ed.), Vygotsky maintenant (pp. 193-211). Paris: La Dispute.

Tartas, V., Baucal, A. \& Perret-Clermont, A.-N. (2010) Can you think with me? The social and cognitive conditions and the fruits of learning. In C. Howe \& K. Littletown (Eds.), Educational Dialogues: Understanding and Promoting Productive Interaction (pp. 64-82). Elsevier Advances in Learning and Instruction Book.

Thompson, V. A., Evans, J. S. B. T., \& Handley, S. J. (2005). Persuading and dissuading by conditional argument. Journal of Memory and Language, 53, 238-257.

Trognon, A. (1993). How does the process of interaction work when two interlocutors try to resolve a logical problem? Cognition \& Instruction, 11(3-4), 325-345.

Tversky, A., \& Kahneman, D. (1983). Extensional versus intuitive reasoning: The conjunction fallacy in probability judgement. Psychological Review, 90, 293-315.

Vallée-Tourangeau, F., \& Krüsi Penney, A. (2005). The impact of external representation in a rule discovery task. European Journal of Cognitive Psychology, 17(6), 820-834.

Valsiner, J. (2007). Thinking as a cultural process. In J. Valsiner (Ed.), Culture in minds and societies: Foundations of cultural psychology (pp. 276-299). New Delhi: Sage.

Van der Henst, J.-B. (2002). Contexte et raisonnement. In G. Politzer (Ed.), Le raisonnement humain (pp. 271-305). Paris: Hermès.

Van der Pal, J., \& Eysink, T. (1999). Balancing situativity and formality: the importance of relating a formal language to interactive graphics in logic instruction. Learning and Instruction, 9, 327-341.

Verzoni, K., \& Swan, K. (1995). On the Nature and Development of Conditional Reasoning in Early Adolescence. Applied Cognitive Psychology, 9, 213-234.

Vygotsky, L. S. (1929). The Problem of the Cultural Development of the Child. The Journal of Genetic Psychology, 36, 415-434.

Vygotsky, L. S. (1978). Mind in society: The development of higher psychological processes. Cambridge, MA: Harvard University Press.

Vygotsky, L. S. (1981). The Genesis of Higher Mental Functions. In J. V. Wertsch (Ed.), The Concept of Activity in Soviet Psychology (pp. 144-188). Armonk, New York: M. E. Sharpe. (Original work 1929)

Vygotsky, L. S. (1986). Thought and language. Cambridge, MA: MIT. (Original work 1934).

Vygotsky, L. S. (1994). The problem of the environment. In R. Van der Veer \& J. Valsiner (Eds.), The Vygotsky Reader (pp. 338-354). Cambridge, MA: Blackwell. (Original work 1935)

Vygotsky, L. S. (2004). Psychologie concrète de 1'homme. In M. Brossard (Ed.), Vygotsky. Lectures et perspectives de recherche en éducation (pp. 225-255). Lille: Presses Universitaires du Septentrion. (Original work 1929)

Ward, S. L., Byrnes, J. P., \& Overton, W. F. (1990). Organization of knowledge and conditional reasoning. Journal of Educational Psychology, 82, 832-837.

Wason, P. C. (1960). On the failure to eliminate hypotheses in a conceptual task. Quarterly Journal of Experimental Psychology, 12, 129-140.

Wason, P. C. (1966). Reasoning. In B. M. Foss (Ed.), New Horizons in Psychology (pp. 135-151). Harmondsworth: Penguin.

Wason, P. C. (1968). Reasoning about a rule. Quarterly Journal of Experimental Psychology, 20, $273-281$.

Wason, P. C. (1977). The Theory of Formal Operations: A Critique. In B. Geber (Ed.), Piaget and Knowing (pp. 119-135). London: Routledge and Kegan Paul.

Wason, P. C., \& Evans, J. S. B. T. (1975). Dual-processes in reasoning? Cognition, 3, 141-154.

Wason, P. C., \& Green, D. W. (1984). Reasoning and mental representation. Quarterly Journal of Experimental Psychology: Section A: Human Experimental Psychology, 36, 597-610.

Wason, P. C., \& Shapiro, D. (1971). Natural and contrived experience in a reasoning problem. Quarterly Journal of Experimental Psychology, 23, 63-71.

Zhou, R. M. (2001). Normes égalitaires, conduites sociales de partage et acquisition de la conservation des quantités. In A. N. Perret-Clermont \& M. Nicolet (Eds.), Interagir et connaître (pp. 187-201). Paris: L'Harmattan.

Zittoun, T. (2008). Learning through transitions: The role of institutions. European Journal of Psychology of Education, 23(2), 165-181.

Zittoun, T., \& Perret-Clermont, A.-N. (2009). Four social psychological lenses for developmental psychology. European Journal of Psychology of Education, 24(3), 387-403. 
Romain Boissonnade is post-doctoral assistant at the University of Neuchatel (Switzerland), where he teaches experimental methodology. He also teaches at the Haute Ecole Pedagogique BEJUNE. His main research interests, situated at the crossroad of sociocognitive and developmental psychologies, are focused on collective and solitary times of work, logical reasoning, children's conceptions in physics, and more recently in engineering education.

Valérie Tartas is professor of Developmental Psychology at the University of Toulouse (France) where she lectures on cultural psychology of thinking and emotions. Her main research interests are the development of knowledge through/in social interactions and of cultural tools in learning contexts. She is also interested in the construction of time in children from a sociocultural approach.

Michèle Guidetti is professor of Developmental Psychology at the University of Toulouse (France). She is the head of the Interdisciplinary Unit of Research Octogone (EA ${ }^{\circ} 4156$ ) which brings together linguists and psychologists at the same University. Her research focuses on developmental pragmatics and multimodal development in children (gestures, emotions and language). 